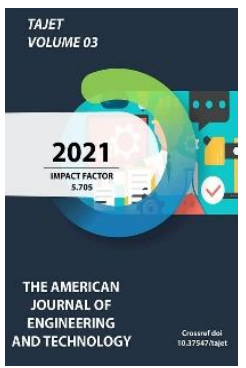

Copyright: Original content from this work may be used under the terms of the creative commons attributes 4.0 licence.

\section{Development Of Aluminum Liquefaction Technology}

\author{
Turakhodjaev Nodir \\ Professor, Head Of Foundry Technologies Department, Tashkent State Technical University, \\ Uzbekistan \\ Tashkhodjaeva Kamola \\ PhD Student, Department Of Foundry Technologies, Tashkent State Technical University, \\ Uzbekistan \\ Abdullaev Kamol \\ Associate Professor, Department Of Machinery Technology Namangan Engineering \\ Construction Institute, Uzbekistan \\ Begmatov Dilmurod \\ Senior Teacher, Department Of Machinery Technology Namangan Engineering Construction \\ Institute, Uzbekistan
}

\title{
ABSTRACT
}

This paper examines the effect of hydrogen gas on the quality of the casting during the liquefaction of aluminum alloy. In addition, the technology for the separation of aluminum from $\mathrm{Al}_{2} \mathrm{O}_{3}$ oxide, depending on the liquefaction temperature during the liquefaction of aluminum alloy.

\section{KEYWORDS}

Aluminum, chemical element, constitute, dissolved, hydrogen, molten, atmosphere.

\section{INTRODUCTION}

Aluminum (Al) chemical element, a lightweight silvery white metal of main Group 13 (III a, or boron group) of the periodic table. Aluminum is the most abundant metallic element in
Earth's crust and the most widely used nonferrous metal. Because of its chemical activity, aluminum never occurs in the metallic form in nature, but its compounds are present 
to a greater or lesser extent in almost all rocks, vegetation, and animals. Aluminum is concentrated in the outer $16 \mathrm{~km}$ (10 miles) of Earth's crust, of which it constitutes about 8 percent by weight; it is exceeded in amount only by oxygen and silicon. The name aluminum is derived from the Latin word alumen, used to describe potash alum, or aluminum potassium sulfate,

$\mathrm{K} \mathrm{Al}\left(\mathrm{SO}_{4}\right)_{2} \cdot 12 \mathrm{H}_{2} \mathrm{O}$.

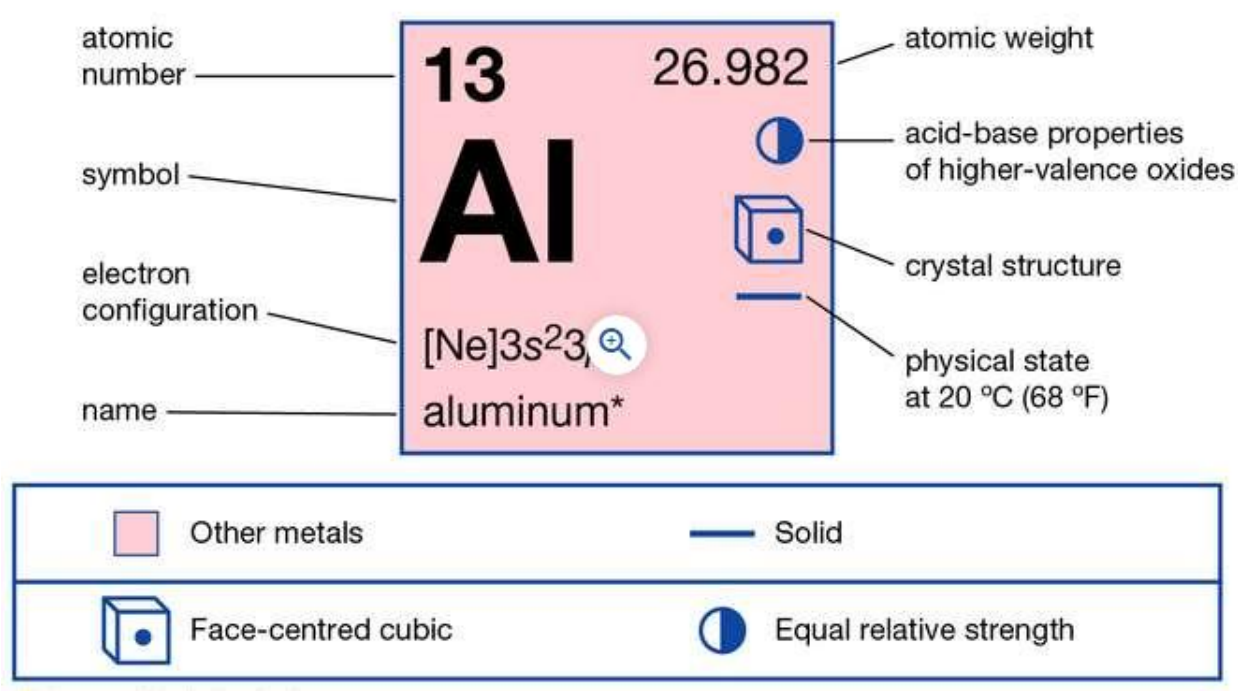

A unique combination of properties puts aluminium and its alloys among our most versatile engineering and construction materials. All alloys are light in weight, yet some have strengths greater than that of structural steel. The majority of alloys are highly durable under the majority of service conditions and no coloured salts are formed to stain adjacent surfaces or discolour products with which they come in contact, such as fabrics in the textile industry and solutions in chemical equipment. They have no toxic reaction. Aluminium and most of its alloys have good electrical and thermal conductivities and high reflectivity to both heat and light. Aluminium and most of its alloys can easily be worked into any form and readily accept a wide variety of surface finishes. Light weight is perhaps the best known characteristic of aluminium, with density of approximately $2.73 \times 10^{3}$ kilograms per cubic meter at $20^{\circ} \mathrm{C}$ as compared with 8.89 $\mathrm{x} 10^{3}$ for copper and $7.86 \times 10^{3}$ for carbon steel.

\section{The source of dissolved hydrogen in molten aluminum}

Only one element of dissolved gas component in aluminum is hydrogen. Hydrogen in molten aluminum $(H)$ has an equilibrium relationship with hydrogen gas in ambient atmosphere. 


$$
H=\frac{1}{2} H_{2}(\text { gas })
$$

Equilibrium constant (KH) of eqn (1) is

$$
K_{\mathrm{H}}=\frac{p_{\mathrm{H} 2}^{\frac{1}{2}}}{f_{\mathrm{H}}[\% H]}
$$

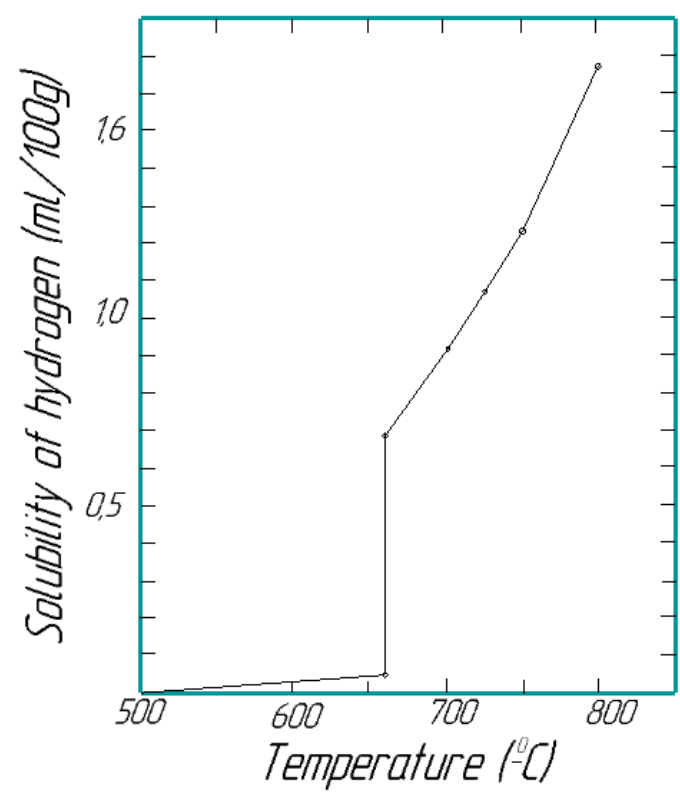

Figure 1 Solubility of hydrogen at 1 atm. in $99.9985 \%$ pure aluminum.

where $f \mathrm{H}$ is the activity coefficient of hydrogen in aluminum, $[\% \mathrm{H}]$ is the hydrogen concentration in aluminum and $\mathrm{P}_{\mathrm{H}_{2}}$ is the partial pressure of hydrogen gas in the atmosphere. Figure 1 [1] shows the equilibrium hydrogen concentration in pure aluminum

with hydrogen gas of 1 bar. (It means the solubility of hydrogen into aluminum under the atmosphere of hydrogen gas partial pressure of $1 \mathrm{~atm}$.) Aluminum reacts with water vapor at high temperature and generates hydrogen gas.

$$
3 \mathrm{H}_{2} \mathrm{O}(\mathrm{g})+2 \mathrm{Al}=\mathrm{Al}_{2} \mathrm{O}_{3}+3 \mathrm{H}_{2}(\mathrm{~g})
$$

This hydrogen gas is the source of hydrogen in aluminum. In the cast house of aluminum industry they often in humid hot season experience more troubles on cast quality for the dissolved hydrogen in the melt. This is due to the chemical reaction between water vapor of higher partial pressure in ambient atmosphere of humid hot season and molten aluminum. Researchers proposed the numerical model of hydrogen pick-up from water vapor and he suggests the hydrogen concentration in molten aluminum which is kept for long time under the atmosphere of a 
constant water vapor pressure $\left(p_{\mathrm{H}_{2} \mathrm{O}}\right)$ should attain to the calculated value.

In this model (Fig. 2), at the interface between molten aluminum and atmosphere, researcher looks at various steps involved as follows.
Water vapor diffuses through the boundary layer to be adsorbed at the metal surface, the adsorbed molecules reacts with aluminum, hydrogen molecules are desorbed from the surface,

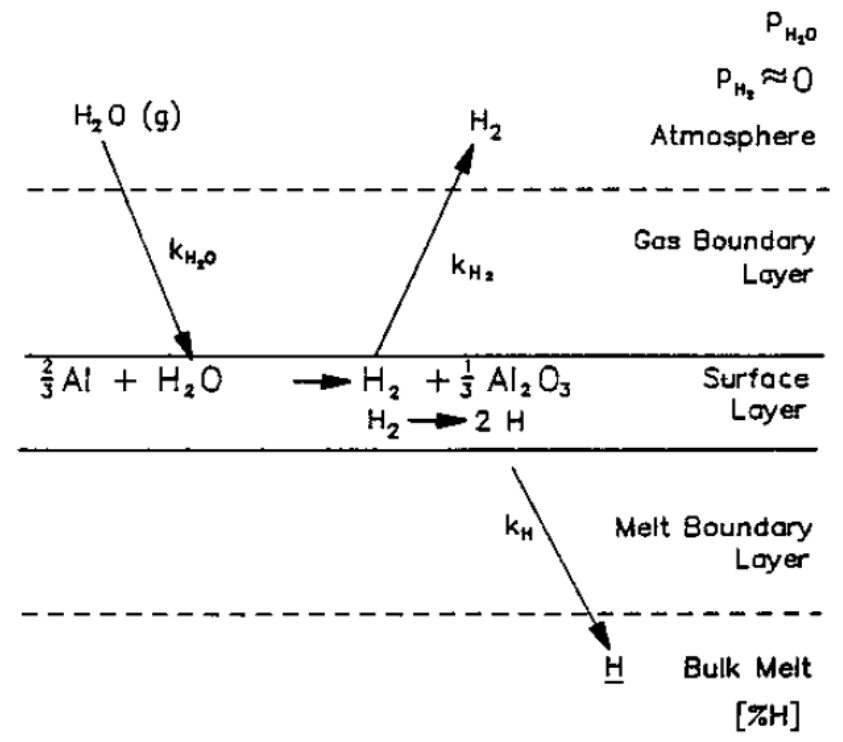

Figure 2. The mechanisms for hydrogen dissolution into the molten aluminum from moisture in the atmosphere.

hydrogen molecules diffuse back out of the boundary layer, hydrogen molecules dissociate and form atomic hydrogen on the surface, hydrogen atoms diffuse through the metal boundary layer. By mathematical analysis of each steps using mass transfer coefficients $k$ at gas-melt interface and the equilibrium constant for in the surface layer, the partial pressure of hydrogen gas $\left(p_{\mathrm{H}_{2}}\right)$ at the interface is given by

$$
p_{\mathrm{H}_{2}}=\frac{k_{\mathrm{H}_{2} \mathrm{O}}}{k_{\mathrm{H}_{2}}} p_{\mathrm{H}_{2} \mathrm{O}}
$$

where $k_{\mathrm{H}_{2} \mathrm{O}}, k_{\mathrm{H}_{2}}$ are mass transfer coefficients for $\mathrm{H}_{2} \mathrm{O}, \mathrm{H}_{2}$ in gas and $p_{\mathrm{H}_{2} \mathrm{O}}$ is the partial pressure of $\mathrm{H}_{2} \mathrm{O}$ in the atmosphere. Therefore, the hydrogen concentration in molten aluminum $([\% \mathrm{H}] \mathrm{I})$ which is kept under the atmosphere of $\mathrm{P}_{\mathrm{H}_{2} \mathrm{O}}$ for long time is calculated from researchers.

$$
[\% H]_{l}=\frac{1}{f_{\mathrm{H}} K_{\mathrm{H}}} \sqrt{\frac{k_{\mathrm{H}_{2} \mathrm{O}} p_{\mathrm{H}_{2} \mathrm{O}}}{k_{\mathrm{H}_{2}}}}
$$




\section{Molten Metal Processing}

The mass transfer coefficients $k_{\mathrm{H}_{2} \mathrm{O}}$ and $k_{\mathrm{H}_{2}}$ can be shown to be proportional to the square root of the diffusion coefficients in air, $D_{\mathrm{H}_{2} \mathrm{O}}$ and $D_{\mathrm{H}_{2}}$. Therefore,

$$
[\% H]_{l} \approx \frac{1}{f_{\mathrm{H}} K_{\mathrm{H}}} \sqrt{p_{\mathrm{H}_{2} \mathrm{O}} \sqrt{\frac{D_{\mathrm{H}_{2} \mathrm{O}}}{D_{\mathrm{H}_{2}}}}}
$$

The diffusion coefficients in air are $D_{\mathrm{H}_{2} \mathrm{O}}=0.239 \mathrm{~cm}^{2} / \mathrm{sec}$ at $8^{\circ} \mathrm{C}$ and $D_{\mathrm{H}_{2}}=0.634 \mathrm{~cm} 2 / \mathrm{sec}$ at $0^{\circ} \mathrm{C}$ [2]. As a first approximation it is assumed that their ratio do not change significantly with temperature. So, we can obtain researchers.

$$
[\% H]_{l} \approx \frac{0.783}{K_{\mathrm{H}}} \sqrt{p_{\mathrm{H}_{2} \mathrm{O}}}
$$

There are few papers which deal with the experimental result of the hydrogen concentration dependence on $\mathrm{P}_{\mathrm{H} 2} \mathrm{O}$. Fig.2. made an experiment to determine the hydrogen pick up of the molten pure aluminum from the water vapor of $\mathrm{P}_{\mathrm{H} 2 \mathrm{O}}$ in the ambient atmosphere. Figure 3 shows the experimental apparatus which can keep the molten metal in the atmosphere of a constant partial pressure of the water vapor. The water vapor partial pressure $\mathrm{P}_{\mathrm{H}_{2} \mathrm{O}}$ was controlled by blowing the dry gas (air or inert gas) of which the dew point is below $-60^{\circ} \mathrm{C}$ through the molecular sieves (in the case of dry air) or the humidified gas through the pure water into the stainless steel box, and the value of $\mathrm{P}_{\mathrm{H}_{2} \mathrm{O}}$ above the melt surface was determined by the measurement of the dew point of the gas blew out of near the melt surface in the box. The temperature of the melts were controlled to $675 \pm 5^{\circ} \mathrm{C}$, $700 \pm 5^{\circ} \mathrm{C}$ or $750 \pm 5^{\circ} \mathrm{C}$. The molten aluminum of 99.99\% pure in the high purity alumina crucible (inner diameter $80 \mathrm{~mm}$, height $170 \mathrm{~mm}$ ) was held in stationary state or stirred state by the rotating graphite impeller (dia. $45 \mathrm{~mm}$, height $30 \mathrm{~mm}$ ) at $530 \mathrm{rpm}$. The hydrogen concentrations of the molten aluminum before and after the treatments were measured by the nitrogen fusion method (I THAC-2002 manufactured by ADAMEL LHOMARGY was used.) for the carefully machined cylindrical samples from the ingots solidified into the Ransley's mould. Figure 4 shows the experimental result of the hydrogen concentration change in the molten pure aluminum which was held at $700^{\circ} \mathrm{C}$ in the dry air atmosphere with $1.7 \times 10^{-4} \mathrm{~atm}$. of $p_{\mathrm{H}_{2} \mathrm{O}}\left(p_{\mathrm{H}_{2} \mathrm{O}}\right.$ in the usual air in Japan is about $1.5 \times 10^{-3}-3.0 \times 10^{-2}$ atm.). The hydrogen concentration of the stationary melt slowly decreases, and after long time holding more than $300 \mathrm{~min}$ it looks like to attain a constant value which may be same as the equilibrium value of hydrogen concentration (0.07ml=100g $=0.07 \mathrm{p}$ : p:m: $)$ which had been attained after about 50 min holding while stirring the melt by rotating impeller. Figure 5 shows the time dependence of the hydrogen concentration in the stirred molten aluminum under the air atmospheres containing various amounts of water vapor. The hydrogen concentration of molten aluminum attains to the equilibrium value depending on $P_{\mathrm{H}_{2} \mathrm{O}}$ irrespective of whether the initial hydrogen 
concentration is lower or higher than the equilibrium one.

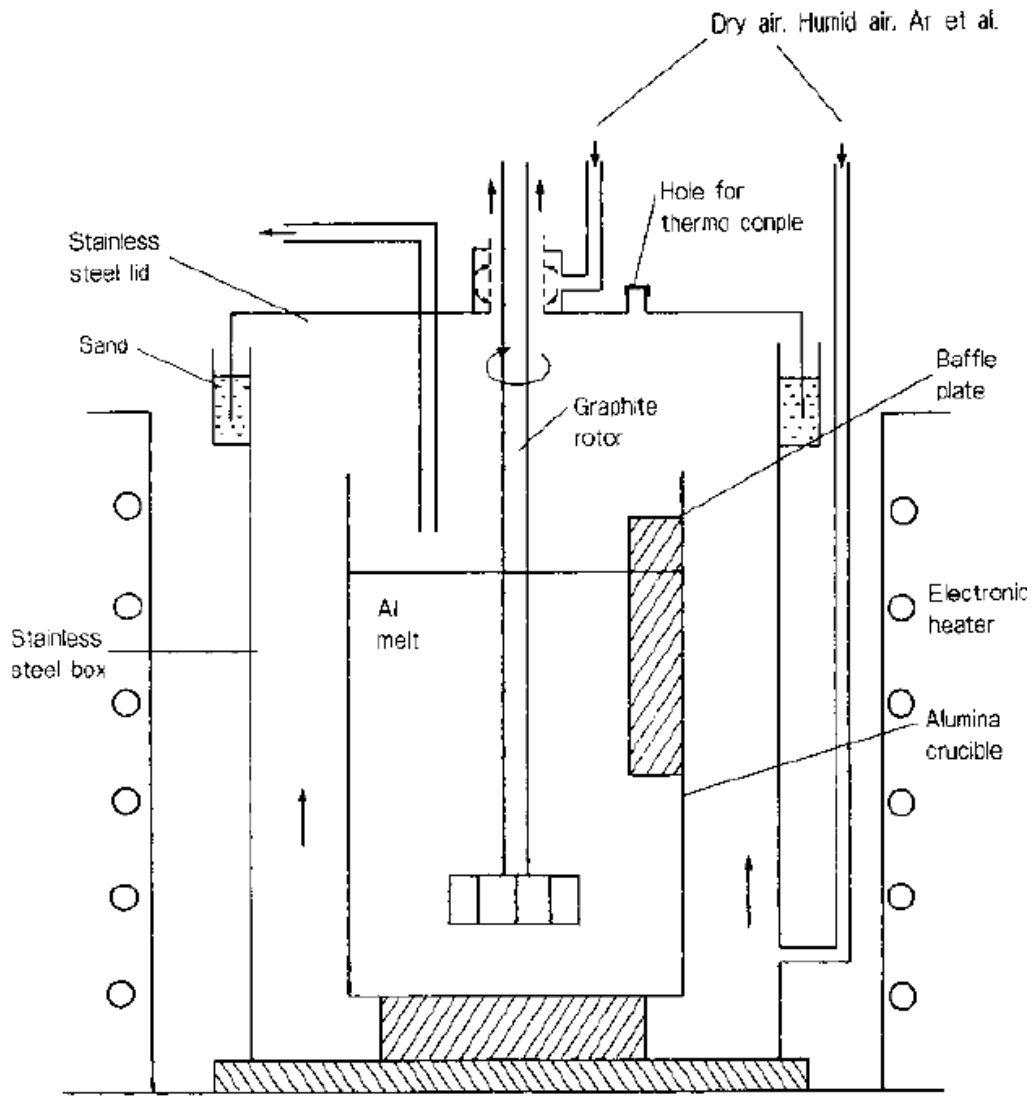

Figure 3. The experimental apparatus for the investigation of hydrogen dissolution into the molten aluminum in the high purity alumina crucible (inner dia. $80 \mathrm{~mm}$, inner height $170 \mathrm{~mm}$ ) from moisture in the atmosphere.

\section{At $675^{\circ} \mathrm{C}$}

$$
\left[H_{e}\right]=3.17 p_{\mathrm{H}_{2} \mathrm{O}} 0.470
$$

\section{At $700^{\circ} \mathrm{C}$}

$$
\left[H_{e}\right]=3.49 p_{\mathrm{H}_{2} \mathrm{O}} 0.453
$$

\section{At $750^{\circ} \mathrm{C}$}

$$
\left[H_{e}\right]=3.16 p_{\mathrm{H}_{2} \mathrm{O}} 0.387
$$

The activation energy of hydrogen solution from water vapor was calculated to be $38806 \mathrm{cal} / \mathrm{mol}$, $30977 \mathrm{cal} / \mathrm{mol}$ and $19467 \mathrm{cal} / \mathrm{mol}$ on each case of $1.0 \times 10^{-2}, 10^{-3}$ and $10^{-4} \mathrm{~atm}$. of $P_{\mathrm{H} 2} \mathrm{O}$. 


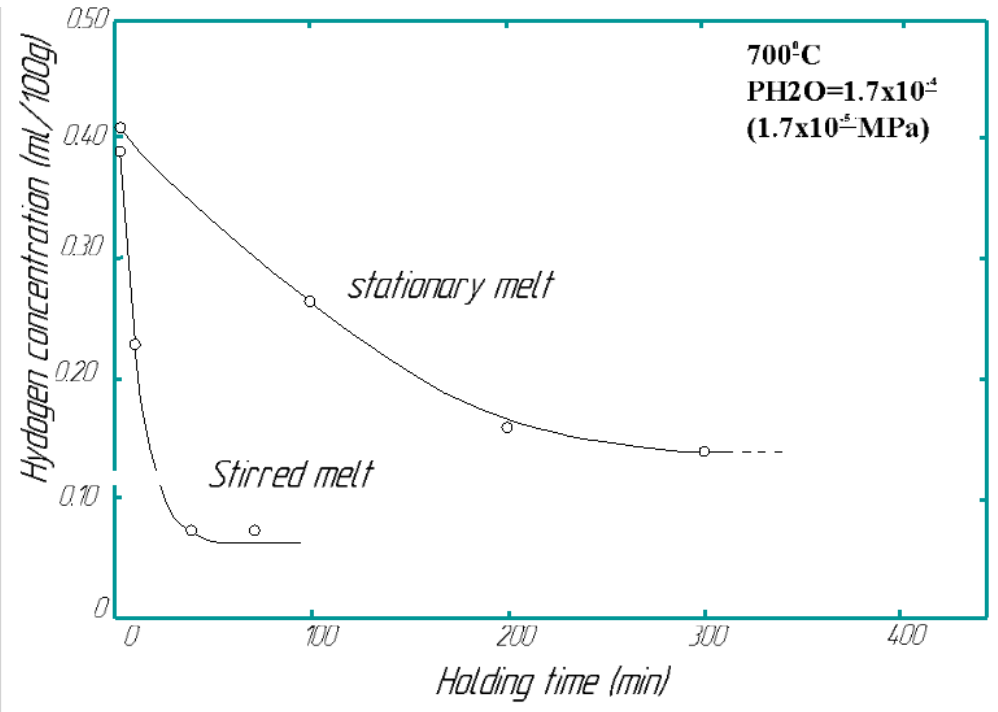

Figure 4. Hydrogen concentration change in molten $99.99 \% \mathrm{Al}$ at $700^{\circ} \mathrm{C}$ under the dry air atmosphere of $P_{\mathrm{H}_{2} \mathrm{O}}=1.7 \times 10^{-4} \mathrm{~atm}$.

They are in rough agreement with the activation energy of hydrogen solution from hydrogen gas, $28258 \mathrm{cal} / \mathrm{mol}$ [3]. These experimental result suggests the pick up of hydrogen from water vapor may occur by the model proposed by researcher and it is limited by slow mass transfer of hydrogen in molten aluminum to the surface, although these experimental values of the equilibrium hydrogen concentration is lager than the calculated value. It is supposed the oxide film of molten aluminum surface may affect the hydrogen pick up of molten aluminum, because the equilibrium hydrogen concentration with $\mathrm{P}_{\mathrm{H}_{2} \mathrm{O}}$ in inert gas atmosphere of $\mathrm{N}_{2}$ or $\mathrm{Ar}$ is lower than in air atmosphere and it is attained earlier than in air atmosphere.

\section{CONCLUSION}

In conclusion, the technology of production of quality castings by reducing hydrogen gas in the process of liquefaction of aluminum alloys has been developed. Hydrogen concentration change in molten $99.99 \% \mathrm{Al}$ at $700^{\circ} \mathrm{C}$ under the dry air atmosphere of $\mathrm{P}_{\mathrm{H} 2 \mathrm{O}}=1.7 \times 10^{-4} \mathrm{~atm}$. These experimental result suggests the pick up of hydrogen from water vapor may occur by the model proposed by researcher and it is limited by slow mass transfer of hydrogen in molten aluminum to the surface, although these experimental values of the equilibrium hydrogen concentration is lager than the calculated value.

\section{REFERENCES}

1. Turakhodjaev N. D. et al. ANALYSIS OF DEFECTS IN WHITE CAST IRON //Theoretical \& Applied Science. - 2020. №. 6. - C. 675-682.

2. Turakhodjaev N. et al. EFFECT OF METAL CRYSTALLATION PERIOD ON PRODUCT QUALITY //Theoretical \& Applied Science. - 2020. - №. 11. - C. 23-31.

a. Djahongirovich T. N., Muysinaliyevich S. N. Important features of casting systems when casting alloy cast irons in sand-clay molds //ACADEMICIA: An International 
Multidisciplinary Research Journal. - 2020.

- T. 10. - №. 5. - C. 1573-1580.

3. Turakhodjaev, N., Turakhujaeva, S.,

Turakhodjaev, S., Tursunbaev, S., Turakhodjaeva, F., \& Turakhujaeva, A. (2020). Research On Heat Exchange In Melting Process. Solid State Technology, 63(6), 6653-6661.

4. Wang, Y., Liao, Y., Wu, R., Turakhodjaev, N., Chen, H., Zhang, J., ... \& Mardonakulov, S. (2020). Microstructure and mechanical properties of ultra-lightweight Mg-Li-Al/AILi composite produced by accumulative roll bonding at ambient temperature. Materials Science and Engineering: $A, 787,139494$.

5. TURAKHODJAEV, N., TURSUNBAEV, S., UMAROVA, D., KUCHKOROVA, M., \& BAYDULLAEV, A. Influence of Alloying Conditions on the Properties of White Cast Iron. International Journal of Innovations in Engineering Research and Technology, 7(12), 1-6.

6. Nodir, T., Sherzod, T., Ruslan, Z., Sarvar, T., \& Azamat, B. (2020). STUDYING THE SCIENTIFIC AND TECHNOLOGICAL BASES FOR THE PROCESSING OF DUMPING COPPER AND ALUMINUM SLAGS. Journal of Critical Reviews, 7(11), 441-444.

7. Турсунбаев, С. А., Зокиров, Р. С., \& Тураев, Х. У. (2017). Влияние обработки деталей из алюминиевого сплава с применением высокоскоростных токарных станков на срок службы резца. In TЕХНИКА И ТЕХНОЛОГИИ МАШИНОСТРОЕНИЯ (рp. 159-163).

8. Wang, Y., Zhong, F., Wu, R., Wu, H., Turakhodjaev, N., Kudratkhon, B., ... \& Zhang, M. (2020). High-strength, ductility and modulus $\mathrm{Al}-\mathrm{Li} / \mathrm{B} 4 \mathrm{C}$ composite with near nanostructure produced by accumulative roll bonding. Journal of Alloys and Compounds, 834, 155105. 